\title{
Molecular Characterization of Hard Ticks by Cytochrome c Oxidase Subunit 1 Sequences
}

\author{
Huitian Gou', Huiwen Xue', Hong Yin², Jianxun Luo ${ }^{2 *}$, Xiaolin Sun ${ }^{1, *}$ \\ ${ }^{1}$ College of Veterinary Medicine, Gansu Agricultural University, Lanzhou, Gansu,730070, P. R. China; ${ }^{2}$ State Key Laboratory of Veterinary Etiological \\ Biology, Lanzhou Veterinary Research Institute of Chinese Academy of Agricultural Science, Lanzhou, Gansu, 730046, P. R. China
}

\begin{abstract}
Although widely studied, the natural diversity of the hard tick is not well known. In this study, we collected 194 sequences from 67 species, covering 7 genera of hard tick. The 5' region of the mitochondrial cytochrome $c$ oxidase subunit 1 region (586 bp) has been used to investigate intra- and inter-species variation and the phylogenetic tree of neighbor joining method has been used for assessment. As a result, by comparing the K2P-distance of intra- and interspecies, 30 samples (15.2\%) shown that interspecies distance was larger than the minimum interspecfic distance. From the phylogenetic analysis, $86.8 \%$ (49) of the species were identified correctly at the genus level. On deeper analysis on these species suggested the possibility of presence cryptic species. Therefore, further work is required to delineate species boundaries and to develop a more complete understanding of hard tick diversity over larger scale.
\end{abstract}

Key words: CO1, hard tick, divergence, phylogenetic analyses

\section{INTRODUCTION}

Hard ticks are obligate ectoparasites, and seem to be second in importance only to mosquitoes as vectors of human and animal diseases [1]. Tick-borne diseases cause a huge loss to the livestock industry and increase the risk of disease such as Lyme disease, babesiosis, human granulocytic ehrlichiosis, forest encephalitis, spotted fever, anaplasmosis, and CrimeanCongo hemorrhagic fever [2-4]. All species are exclusively hematophagous in all feeding stages. Hard ticks are distributed worldwide with their hosts range from wild to domestic vertebrates except fishes.

Traditionally, classifications and phylogenetic inferences for Ixodidae were based on morphological, biological and ecological characteristics, often suggesting host specificity as the main factor $[5,6]$. However, methods for species determination are limited when taxa are morphologically very similar, specimens are damaged, and in frequent cases where immature stages are not described or are engorged [7].

Molecular systematics offered new possibilities to improve

\footnotetext{
- Received 2 February 2018, revised 20 April 2018, accepted 25 April 2018.

*Corresponding authors (vectorparasit@126.com; sunxl@gsau.edu.cn)

(C) 2018, Korean Society for Parasitology and Tropical Medicine

This is an Open Access article distributed under the terms of the Creative Commons Attribution Non-Commercial License (http://creativecommons.org/licenses/by-nc/4.0) which permits unrestricted non-commercial use, distribution, and reproduction in any medium, provided the original work is properly cited.
}

species recognition in hard ticks. ITS, $18 \mathrm{~S}$ rDNA, $28 \mathrm{~S}$ rDNA and other mitochondrial rDNA genes have been used to study these organisms and have played an important role in analyzing the classification and phylogenetics of hard ticks [8-10]. However, compared to the number of species of hard ticks, the extent of these studies are very limited [11].

Until recently, there has been little effort to standardize the methods for molecular identification of hard ticks, and no one gene has been formally selected as an admitted DNA marker to deal with problems of classification and phylogenetics in hard ticks. So, we chose the mitochondrial cytochrome $c$ oxidase subunit 1 (CO1) gene fragment as a candidate molecular marker, and collected 194 samples (from 67 species of 7 genera) of hard ticks. Intra- and interspecies genetic divergences were assessed using the Kimura 2-parameter (K2P) distance model. Phylogenetic tree were performed to analyse their relationship at evolutionary level.

\section{MATERIALS AND METHODS}

\section{Sample collection}

Ticks used in this study were collected from field sites and different hosts in various regions of China (Table 1). After morphological identification, ticks were stored in 100\% ethanol and conserved at $4^{\circ} \mathrm{C}$. Only male and unfed adult specimens were used. 
Table 1. Details of 36 samples collected from China in this study

\begin{tabular}{|c|c|c|c|c|}
\hline Genus & Species & Time & Locality & Source \\
\hline Hyalomma & $\begin{array}{l}\text { Hya. dromedarii } \\
\text { Hya.anatolicum anatolicum } \\
\text { Hya. detritum } \\
\text { Hya. asiaticum asiaticum } \\
\text { Hya. asiaticum asiaticum } \\
\text { Hya. asiaticum } \\
\text { Hya. rufipes }\end{array}$ & $\begin{array}{l}\text { Sep. } 2010 \\
\text { Unknown } \\
\text { Unknown } \\
\text { Unknown } \\
\text { Jun. } 2010 \\
\text { Jun. } 2011 \\
\text { Jul. } 2010\end{array}$ & $\begin{array}{c}\text { Gansu } \\
\text { Gansu } \\
\text { Inner Mongolia } \\
\text { Inner Mongolia } \\
\text { Xinjiang } \\
\text { Gansu } \\
\text { Gansu }\end{array}$ & $\begin{array}{l}\text { Camel } \\
\text { Unknown } \\
\text { Unknown } \\
\text { Ground } \\
\text { Cattle } \\
\text { Camel } \\
\text { Goat }\end{array}$ \\
\hline Dermacentor & $\begin{array}{l}\text { D. silvarum } \\
\text { D. silvarum } \\
\text { D. silvarum } \\
\text { D. silvarum } \\
\text { D. silvarum } \\
\text { D. everestianus } \\
\text { D. niveus }\end{array}$ & $\begin{array}{l}\text { Apr. } 2010 \\
\text { Apr. } 2010 \\
\text { Apr. } 2010 \\
\text { May. } 2011 \\
\text { May. } 2011 \\
\text { May. } 2011 \\
\text { Jun. } 2011\end{array}$ & $\begin{array}{l}\text { Gansu } \\
\text { Gansu } \\
\text { Gansu } \\
\text { Gansu } \\
\text { Gansu } \\
\text { Xizang } \\
\text { Xizang }\end{array}$ & $\begin{array}{l}\text { Sheep } \\
\text { Goat } \\
\text { Sheep } \\
\text { Sheep } \\
\text { Sheep } \\
\text { Sheep } \\
\text { Sheep }\end{array}$ \\
\hline Rhipicephalus & $\begin{array}{l}\text { R. microplus } \\
\text { R. microplus } \\
\text { R. sanguinens } \\
\text { R.haemaphysaloides haemaphysaloides } \\
\text { R. turanicus }\end{array}$ & $\begin{array}{l}\text { Jun. } 2011 \\
\text { Jun. } 2010 \\
\text { May. } 2010 \\
\text { Jun. } 2011 \\
\text { May. } 2010\end{array}$ & $\begin{array}{l}\text { Gansu } \\
\text { Guizhou } \\
\text { Guangxi } \\
\text { Sichuan } \\
\text { Xinjiang }\end{array}$ & $\begin{array}{l}\text { Cattle } \\
\text { Cattle } \\
\text { Dog } \\
\text { Goat } \\
\text { Sheep }\end{array}$ \\
\hline Haemaphysalis & $\begin{array}{l}\text { H. longicornis } \\
\text { H. longicornis } \\
\text { H. longicornis } \\
\text { H. longicornis } \\
\text { H. longicornis } \\
\text { H. longicornis } \\
\text { H. qinghaiensis } \\
\text { H. qinghaiensis } \\
\text { H. qinghaiensis } \\
\text { H. qinghaiensis } \\
\text { H. qinghaiensis } \\
\text { H. qinghaiensis } \\
\text { H. flava }\end{array}$ & $\begin{array}{l}\text { May. } 2011 \\
\text { Sep. } 2010 \\
\text { Unknown } \\
\text { May. } 2010 \\
\text { Jun. } 2011 \\
\text { May. } 2010 \\
\text { Apr. } 2010 \\
\text { May. } 2010 \\
\text { May. } 2011 \\
\text { Jun. } 2011 \\
\text { Jun. } 2011 \\
\text { May. } 2008 \\
\text { Sep. } 2010\end{array}$ & $\begin{array}{l}\text { Anhui } \\
\text { Henan } \\
\text { Gansu } \\
\text { Hubei } \\
\text { Gansu } \\
\text { Zhejiang } \\
\text { Gansu } \\
\text { Gansu } \\
\text { Gansu } \\
\text { Qinghai } \\
\text { Qinghai } \\
\text { Gansu } \\
\text { Henan }\end{array}$ & $\begin{array}{l}\text { Goat } \\
\text { Sheep } \\
\text { Sheep } \\
\text { Sheep } \\
\text { Sheep } \\
\text { Sheep } \\
\text { Sheep } \\
\text { Sheep } \\
\text { Sheep } \\
\text { Ground } \\
\text { Sheep } \\
\text { Ground } \\
\text { Sheep }\end{array}$ \\
\hline Ixodes & I. persulcatus & Jun. 2011 & Xinjiang & Sheep \\
\hline
\end{tabular}

\section{DNA extraction, PCR amplification, and sequencing of $\mathrm{CO} 1$}

DNA was extracted from the ticks using a tissue kit (Qiagen AG, Basel,Switzerland) according to the manufacturer's instructions. Each sample was cut with sterile scissors within a $1.5 \mathrm{ml}$ microtube. After digestion with proteinase $\mathrm{K}(20 \mathrm{mg} / \mathrm{ml})$, the samples were applied to the columns for DNA absorption and washing. Finally, the DNA was eluted in $100 \mathrm{ml}$ of eluting buffer provided in the kit and stored at $-20^{\circ} \mathrm{C}$. The primers used for PCR were LCO1490 (5'-GGTCAACAAATCATAAAGATA- TTGG$\left.3^{\prime}\right)$ and HCO2198 (5'-TAAACTTCAGGGTGACCAAAAAATCA-3') [12]. The $5^{\prime}$ region of $\mathrm{CO} 1$ was amplified using the following thermal cycling program: $94^{\circ} \mathrm{C}$ for $5 \mathrm{~min}, 35$ cycles at $94^{\circ} \mathrm{C}$ for 1 $\min , 53^{\circ} \mathrm{C}$ for $1 \mathrm{~min}$, and $72^{\circ} \mathrm{C}$ for $1 \mathrm{~min}$, followed by a final extension at $72^{\circ} \mathrm{C}$ for $8 \mathrm{~min}$. PCR products were purified using a PCR purification kit (Takara, Shiga, Japan). Sequencing reactions were resolved on automated DNA sequencer.

\section{Data from GenBank}

Some $\mathrm{CO} 1$ sequences from the hard ticks were downloaded from GenBank. Sequences < 500 bp in length, with ambiguous bases (more than 15 'Ns'), or those belonging to unnamed species (sequences with 'sp.' in the species name) were removed from the analysis. In addition, we checked all the sequences using BLAST analysis ( $E$-value $<0.001)$ to make sure that there were no host sequences in our data. The selected sequences were used to construct analysis datasets.

\section{Sequence analysis}

The CO1 sequences were translated into amino acids with the program MEGA 4.0 in order to exclude sequencing errors and to avoid the inclusion of pseudogene sequences in the datasets. The sequences were aligned using ClustalW [13], and genetic distances were computed using MEGA 4.0 according to the K2P distance model. The maximal/mean/minimum intra- and interspecies distances were used to represent species 
level divergence. Meanwhile, the maximal/mean/minimum intra-and intergenus distances were calculated to evaluate the genus level variation. Then a neighbor joining (NJ) tree was constructed and the genetic K2P distance was calculated within species and genera using MEGA 4.0. Evaluation of statistical confidence was based on 1,000 non-parametric bootstrap replicates. One soft tick isolate was used as the outgroup of phylogenetic tree.

\section{RESULTS}

\section{Data acquisition}

We collected 194 samples (36 from this study, 158 from GenBank) from 67 species and 7 genera of hard ticks (Table 1 and Supplementary Table S1). The mitochondrial CO1 region of all samples collected in China was successfully amplified using PCR. The length of the PCR product was $707 \mathrm{bp}$. As some sequences of the $\mathrm{CO} 1$ gene obtained from GenBank were shorter than $707 \mathrm{bp}$, all sequences were aligned with a consensus length of $586 \mathrm{bp}$, and no insertions, deletions, or stop codons were observed in any sequence. The sequences acquired in this study have been deposited in the GenBank database with accession numbers JQ737066-JQ737128.

\section{Genetic divergence and gap}

Using the K2P model, sample divergences at various taxonomic levels are shown in Tables 2 and 3. As expected, the genetic divergence increased with higher taxonomic ranking: $0.001 \pm 0.001$ to $0.016 \pm 0.003$ at intraspecies level, $0.002 \pm 0.001$ to $0.248 \pm 0.023$ at interspecies level, $0.005 \pm 0.002$ to $0.175 \pm 0.011$ at intragenus level, and $0.186 \pm 0.012$ to $0.243 \pm 0.016$ at intergenus level. The Bothriocroton showed the lowest mean intraspecies divergence $(0.005 \pm 0.002)$, while Rhipicephalus showed the highest mean intraspecies divergence $(0.062 \pm 0.039)$ (Fig. 1). The largest ratio between the average intra- and interspecies divergence was in the Ixodes with a 7.5-fold difference, and the lowest ratio was in the Dermacentor with a 2.4-fold difference. As shown in Fig. 1, there was not a distinct gap between the distribution of the intra- and interspecies divergence. The overlapping regions were mainly distributed in the R. turanicus, Hya. dromedarii, D. marginatus, D. silvarum, and $A$. testudinarium.

\section{Phylogenetic tree}

The NJ tree of the overall analysis is shown in Fig. 2. The phylogenetic relationship at the genus level was well resolved

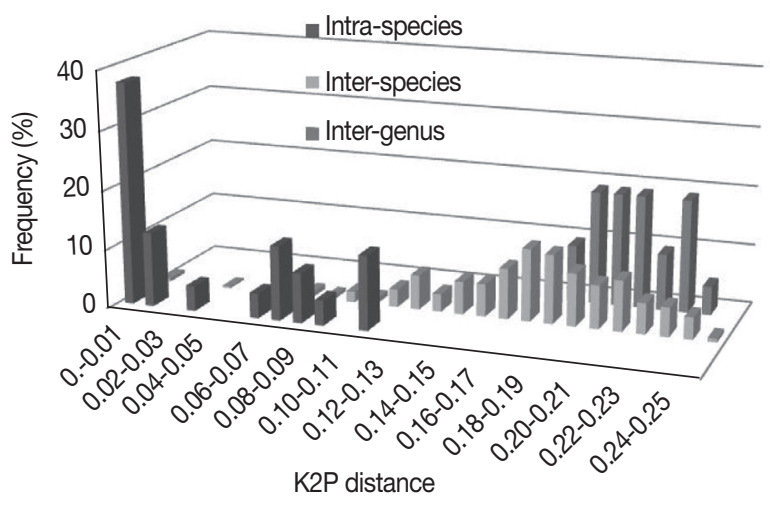

Fig. 1. Frequency distribution of genetic K2P-distances in a 586 bp segment of the CO1 gene in Ixodidae at species and genus level.

Table 2. Measures of inter- and intra-species divergences for CO1 sampled in 7 genera of Ixodidae

\begin{tabular}{|c|c|c|c|c|c|c|}
\hline & \multicolumn{3}{|c|}{ Intra-species distance } & \multicolumn{3}{|c|}{ Inter-species distance } \\
\hline & Minimum & Mean & Maximum & Minimum & Mean & Maximum \\
\hline Hyalomma & $0.004 \pm 0.002$ & $0.039 \pm 0.046$ & $0.110 \pm 0.010$ & $0.035 \pm 0.006$ & $0.113 \pm 0.027$ & $0.155 \pm 0.017$ \\
\hline Dermacentor & $0.003 \pm 0.001$ & $0.050 \pm 0.042$ & $0.084 \pm 0.008$ & $0.002 \pm 0.001$ & $0.122 \pm 0.058$ & $0.179 \pm 0.016$ \\
\hline Haemaphysalis & $0.008 \pm 0.002$ & $0.033 \pm 0.042$ & $0.016 \pm 0.003$ & $0.150 \pm 0.016$ & $0.175 \pm 0.021$ & $0.191 \pm 0.019$ \\
\hline Bothriocroton & $0.005 \pm 0.002$ & $0.005 \pm 0.002$ & $0.005 \pm 0.002$ & $0.000 \pm 0.000$ & $0.000 \pm 0.000$ & $0.000 \pm 0.000$ \\
\hline Amblyomma & $0.002 \pm 0.002$ & $0.057 \pm 0.077$ & $0.112 \pm 0.010$ & $0.147 \pm 0.016$ & $0.177 \pm 0.028$ & $0.206 \pm 0.018$ \\
\hline Ixodes & $0.001 \pm 0.001$ & $0.026 \pm 0.043$ & $0.077 \pm 0.010$ & $0.094 \pm 0.017$ & $0.196 \pm 0.030$ & $0.248 \pm 0.023$ \\
\hline
\end{tabular}

Table 3. Measures of inter- and intragenus divergences for CO1 sampled in family Ixodidae

\begin{tabular}{|c|c|c|c|c|c|c|}
\hline & \multicolumn{3}{|c|}{ Intra-genus distance } & \multicolumn{3}{|c|}{ Inter-genus distance } \\
\hline & Minimum & Mean & Maximum & Minimum & Mean & Maximum \\
\hline Ixodidae & $0.005 \pm 0.002$ & $0.118 \pm 0.056$ & $0.175 \pm 0.011$ & $0.186 \pm 0.012$ & $0.211 \pm 0.017$ & $0.243 \pm 0.016$ \\
\hline
\end{tabular}




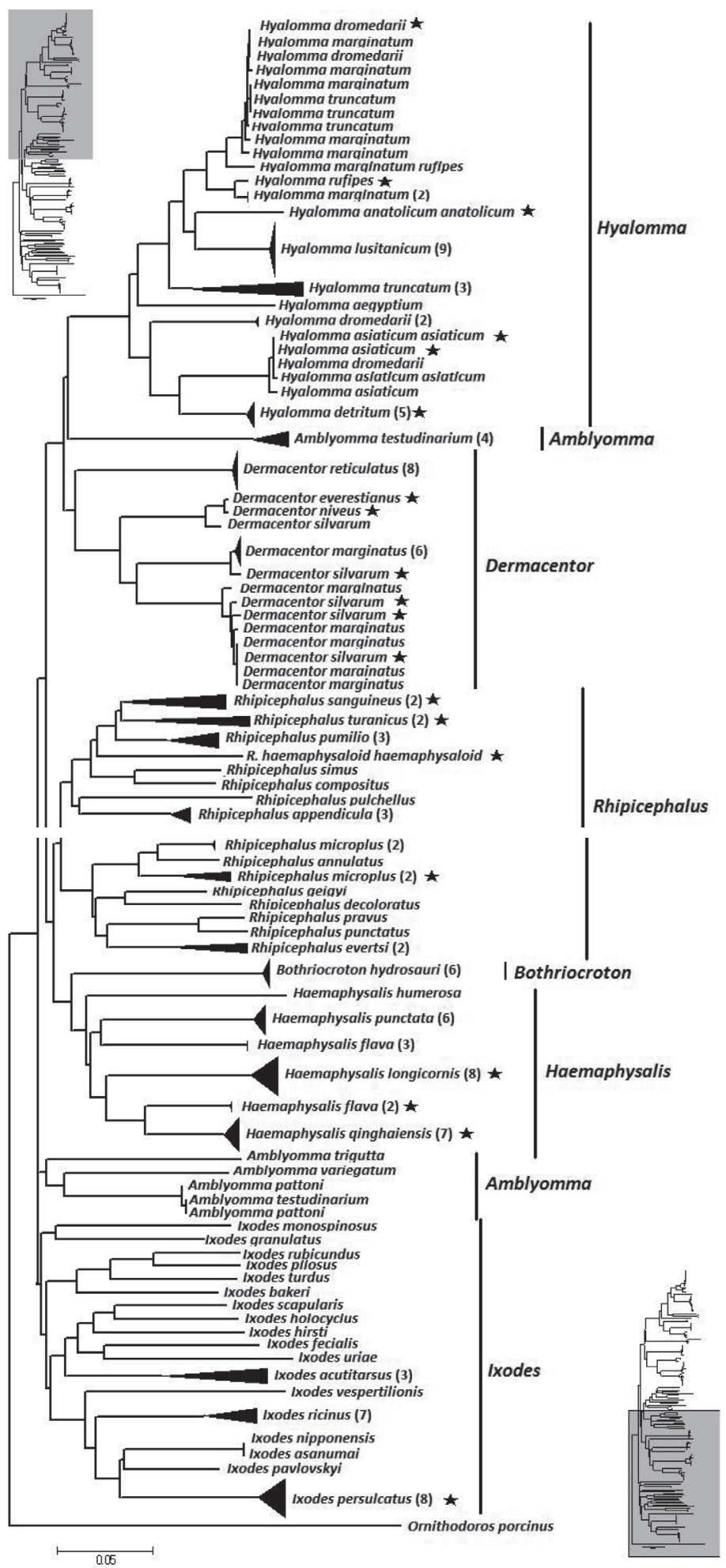

Fig. 2. Neighbor-joining tree of 194 isolates from the family Ixodidae and related species. The tree is constructed with 586 bp of CO1. Bracketed numbers represent the number of isolates sequenced for each species. Asterisk represent samples collected from China in this study. 
with the exception of Amblyomma. From the tree, Hyalomma, Dermacentor, Amblyomma, and Rhipicephalus formed 1 clade. Bothriocroton and Haemaphysalis formed another clade. Ixodes as distinct difference at morphous to other hard ticks, formed a third clade. However, at a species level, 9 species (13.4\%) did not form a monophyletic group. They were Hya. dromedarii, Hya. marginatum, Hya. asiaticum asiaticum, D. marginatus, D. silvarum, A. testudinarium, R. microplus, and $H$. flava.

\section{DISCUSSION}

In this study, the mean sequence divergence in hard ticks $(0.197 \pm 0.063)$ is higher than that observed in other organisms [14-16]. Such high values of genetic distance reflect possible biological diversity within the Ixodidae. Such as the distance between Amblyomma testudinarium (HM193893) and A. testudniarium (HM193895) was $0.112 \pm 0.010$, and they were in different clades of the phylogenetic tree. However, Rhipicephalus microplus and Dermacentor marginatus also gave similar results. The reason may be geographic variation or comprise cryptic species [17]. Additionally, the distance between the species Dermacentor everestianus (JQ737079) and D. niveus (JQ737080) was only $0.004 \pm 0.002$, and also formed into 1 clade. Therefore, these analyses might indicate hybridization or a misidentification among these species.

The CO1 gene appears to be an informative molecular marker on several taxonomic scales, but particularly at the species level [18]. Our analysis shows a general increase in the molecular divergence of $\mathrm{CO} 1$ with taxonomic rank. The diversity within species is especially high, with a maximum of $0.116 \pm 0.015$. It makes $\mathrm{CO} 1$ suitable for investigating intraspecies variation. DNA barcoding assumes that the genetic distances between species are greater than within species. In that way, clusters of similar sequences represent species, clearly separated from other clusters (species) [19]. However, there also 30 samples where the maximum interspecies distance was larger than the minimum interspecfic distance. This means that the gap might be absent in these samples because of insufficient variation between them $[20,21]$. From the NJ phylogenetic tree, nine of the 67 species (13.4\%) examined in this study (Hya. dromedarii, Hya. marginatum, Hya. asiaticum asiaticum, Hya. truncatum, D. marginatus, D. silvarum, A. testudinarium, R. microplus, and $H$. flava.) did not form a monophyletic group. Hya. asiaticum asiaticum and Hya. dromedarii shared similar morphologic characters from capitulum, scutum,
Haller's organ, peritrematal plate, the first caruncle, coax and spur of feet of adults and larval stages. Ecologically, these 2 species also share the same desert intertidal area. They are 2 different species proved by previous studies [22-24]. However, they formed one clade in this study. This phenomenon was also found for other hard ticks. For example, Hya. dromedarii, Hya. marginatum and Hya. truncatum formed a complex clade. These results agreed with some studies using mt $12 \mathrm{~S}$ rDNA, $16 \mathrm{~S}$ rDNA or ITS, in which Hyalomma spp. shown high divergence distance and low bootstrap value $[25,26]$. As many results indicated that there is a high diversity in hard ticks $[27,28]$.

This study provides that using the $\mathrm{CO} 1$ gene is a potential tool for species identification in Ixodidae. However, it is inadequate to use a single mitochondrial gene (CO1) for DNA taxonomy. Therefore, an integrative approach is needed to combine nuclear and mitochondrial genes, morphological characters, and ecological information into further studies of hard ticks.

\section{ACKNOWLEDGMENTS}

This work was supported by the NSFC (No. 31560700), Provincial characteristic discipline open fund of Veterinary Medicine College, Gansu Agricultural University (GAU-XKJS-2018 -08), Sheng Tongsheng innovation fund of Gansu Agricultural University (GSAU-STS-1422). The research was also facilitated by Specific Fund for Innovative Talent of Lanzhou City (No. 2014-2-11). We are indebted to international science editing for critical correction of this manuscript.

\section{CONFLICT OF INTEREST}

All authors declare that they have no conflicts of interest.

\section{REFERENCES}

1. Jongejan F, Uilenberg G. The global importance of ticks. Parasitology 2004; 129 (suppl): 3-14.

2. Banumathi B, Vaseeharan B, Rajasekar P, Prabhu NM, Ramasamy P, Murugan K, Canale A, Benelli G. Exploitation of chemical, herbal and nanoformulated acaricides to control the cattle tick, Rhipicephalus (Boophilus) microplus - A review. Vet Parasitol 2017; 244: 102-110.

3. Chen Z. Taxonomic and Systematic Research of Chinese Ticks and Biological Characteristic Analysis of Two Hard Tick Species. 
Shijiazhuang, China. Hebei Normal University 2010.

4. Estrada-Peña A, Ayllón N, de la Fuente J. Impact of climate trends on tick-borne pathogen transmission. Front Physiol 2012; 3: 64 .

5. McCoy KD, Léger E, Dietrich M. Host specialization in ticks and transmission of tick-borne diseases: a review. Front Cell Infect Microbiol 2013; 3: 57.

6. Klompen JS, Black WC 4th, Keirans JE, Oliver JH Jr. Evolution of ticks. Annu Rev Entomol 1996; 41: 141-161.

7. Nava S, Guglielmone AA, Mangold AJ. An overview of systematics and evolution of ticks. Front Biosci 2009; 14: 2857-2877.

8. Li HY, Zhao SS, Hornok S, Farkas R, Guo LP, Chen CF, Shao RF, Lv JZ, Wang YZ. Morphological and molecular divergence of Rhipicephalus turanicus tick from Albania and China. Exp Appl Acarol 2017; 73: 493-499.

9. Livanova NN, Tikunov AY, Kurilshikov AM, Livanov SG, Fomenko NV, Taranenko DE, Kvashnina AE, Tikunova NV. Genetic diversity of Ixodes pavlovskyi and I. persulcatus (Acari: Ixodidae) from the sympatric zone in the south of Western Siberia and Kazakhstan. Exp Appl Acarol 2015; 67: 441-456.

10. Marrelli MT, Souza LF, Marques RC, Labruna MB, Matioli SR, Tonon AP, Ribolla PE, Marinotti O, Schumaker TT. Taxonomic and phylogenetic relationships between neotropical species of ticks from genus Amblyomma (Acari: Ixodidae) inferred from second internal transcribed spacer sequences of rDNA. J Med Entomol 2007; 44: 222-228.

11. Chitimia L, Lin RQ, Cosoroaba I, Wu XY, Song HQ, Yuan ZG, Zhu XQ. Genetic characterization of ticks from southwestern Romania by sequences of mitochondrial cox 1 and nad5 genes. Exp Appl Acarol 2010; 52: 305-311.

12. Folmer O, Black M, Hoeh W, Lutz R, Vrijenhoek R. DNA primers for amplification of mitochondrial cytochrome c oxidase subunit I from diverse metazoan invertebrates. Mol Mar Biol Biotechnol. 1994; 3: 294-299.

13. Thompson JD, Higgins DG, Gibson TJ. CLUSTAL W: improving the sensitivity of progressive multiple sequence alignment through sequence weighting, position-specific gap penalties and weight matrix choice. Nucleic Acids Res 1994; 22: 4673-4680.

14. Matzen da Silva J, Creer S, dos Santos A, Costa AC, Cunha MR, Costa FO, Carvalho GR. Systematic and Evolutionary Insights Derived from mtDNA CO1 Barcode Diversity in the Decapoda (Crustacea: Malacostraca). PLoS One 2011; 6: e19449.

15. Kerr KC, Stoeckle MY, Dove CJ, Weigt LA, Francis CM, Hebert PD. Comprehensive DNA barcode coverage of North American birds. Mol Ecol Notes 2007; 7: 535-543.

16. Ros VI, Breeuwer JA. Spider mite (Acari: Tetranychidae) mitochondrial CO1 phylogeny reviewed: host plant relationships, phylogeography, reproductive parasites and barcoding. Exp Appl Acarol 2007; 42: 239-262.

17. Rees DJ, Dioli M, Kirkendall LR. Molecules and morphology: evidence for cryptic hybridization in African Hyalomma (Acari: Ixodidae). Mol Phylogenet Evol 2003; 27: 131-142.

18. Waugh J. DNA barcoding in animal species: progress, potential and pitfalls. Bioessays 2007; 29: 188-197.

19. Hebert PD, Ratnasingham S, deWaard JR. Barcoding animal life: cytochrome c oxidase subunit 1 divergences among closely related species. Proc Biol Sci 2003; 270 (suppl): 96-99.

20. Sheth BP, Thaker VS. DNA barcoding and traditional taxonomy: an integrated approach for biodiversity conservation. Genome 2017; 60: 618-628.

21. Meyer CP, Paulay G. DNA barcoding: error rates based on comprehensive sampling. PLoS Biol 2005; 3: e422.

22. Apanaskevich DA, Horak IG. The genus Hyalomma. XI. Redescription of all parasitic stages of $H$. (Euhyalomma) asiaticum (Acari: Ixodidae) and notes on its biology. Exp Appl Acarol 2010; 52: 207-220.

23. Apanaskevich DA, Schuster AL, Horak IG. The genus Hyalomma: VII. Redescription of all parasitic stages of H.(Euhyalomma) dromedarii and H.(E.) schulzei (Acari: Ixodidae). J Med Entomol 2008; 45: 817-831.

24. Chen Z, Yu Z, Yang X, Zheng H, Liu J. The life cycle of Hyalomma asiaticum kozlovi Olenev, 1931 (Acari: Ixodidae) under laboratory conditions. Vet Parasitol 2009; 160: 134-137.

25. Kaur H, Chhilar JS, Chhillar S. Mitochondrial 16S rDNA based analysis of some hard ticks belonging to genus Hyalomma Koch, 1844 (Acari: Ixodidae). J Adv Parasitol 2016; 3: 32-48.

26. Hekimoglu O, Ozer AN. Distribution and phylogeny of Hyalomma ticks (Acari: Ixodidae) in Turkey. Exp Appl Acarol 2017; 73: 501-519.

27. Bursali A, Keskin A, Tekin S. A review of the ticks (Acari: Ixodida) of Turkey: species diversity, hosts and geographical distribution. Exp Appl Acarol 2012; 57: 91-104.

28. Shemshad K, Rafinejad J, Kamali K, Piazak N, Sedaghat MM, Shemshad M, Biglarian A, Nourolahi F, Valad Beigi E, Enayati AA. Species diversity and geographic distribution of hard ticks (Acari: Ixodoidea: Ixodidae) infesting domestic ruminants, in Qazvin Province, Iran. Parasitol Res 2012; 110: 373-380. 
Supplementary Table S1. The taxa and GenBank accession of 194 hard ticks used in this study

\begin{tabular}{|c|c|c|}
\hline Taxon & Locality & GeneBank accessions \\
\hline Amblyomma limbatum & Australian & FJ584434 \\
\hline Amblyomma limbatum & Australian & FJ584430 \\
\hline Amblyomma limbatum & Australian & FJ584435 \\
\hline Amblyomma limbatum & Australian & FJ584433 \\
\hline Amblyomma limbatum & Australian & FJ584429 \\
\hline Amblyomma pattoni & China & HM193875 \\
\hline Amblyomma pattoni & China & HM193876 \\
\hline Amblyomma testudinarium & China & HM193895 \\
\hline Amblyomma testudinarium & China & HM193893 \\
\hline Amblyomma testudinarium & China & HM193894 \\
\hline Amblyomma testudinarium & China & HM193892 \\
\hline Amblyomma trigutta & Japan & AB113317 \\
\hline Amblyomma variegatum & Senegal & GU062743 \\
\hline Bothriocroton hydrosauri & Australian & FJ584426 \\
\hline Bothriocroton hydrosauri & Australian & FJ584424 \\
\hline Bothriocroton hydrosauri & Australian & FJ584422 \\
\hline Bothriocroton hydrosauri & Australian & FJ584427 \\
\hline Bothriocroton hydrosauri & Australian & FJ584425 \\
\hline Bothriocroton hydrosauri & Australian & FJ584423 \\
\hline Dermacentor albipictus & Canada & GU968842 \\
\hline Dermacentor everestianus & China & JQ737079 \\
\hline Dermacentor marginatus & Romania & FN394327 \\
\hline Dermacentor marginatus & Romania & FN394331 \\
\hline Dermacentor marginatus & Romania & FN394332 \\
\hline Dermacentor marginatus & Romania & FN394330 \\
\hline Dermacentor marginatus & Romania & FN394328 \\
\hline Dermacentor marginatus & China & HM193891 \\
\hline Dermacentor marginatus & China & HM193889 \\
\hline Dermacentor marginatus & China & HM193887 \\
\hline Dermacentor marginatus & China & HM193890 \\
\hline Dermacentor niveus & China & JQ737080 \\
\hline Dermacentor reticulatus & China & HM193885 \\
\hline Dermacentor reticulatus & China & HM193883 \\
\hline Dermacentor reticulatus & China & HM193881 \\
\hline Dermacentor reticulatus & China & HM193879 \\
\hline Dermacentor reticulatus & China & HM193886 \\
\hline Dermacentor reticulatus & China & HM193884 \\
\hline Dermacentor reticulatus & China & HM193882 \\
\hline Dermacentor silvarum & China & JQ737075 \\
\hline Dermacentor silvarum & China & JQ737076 \\
\hline Dermacentor silvarum & China & JQ737077 \\
\hline Dermacentor silvarum & China & JQ737078 \\
\hline Dermacentor silvarum & China & JQ737081 \\
\hline Dermacentor steini & China & HM193861 \\
\hline Haemaphysalis concinna & China & EU670047 \\
\hline Haemaphysalis flava & China & JQ737097 \\
\hline Haemaphysalis flava & China & HM193864 \\
\hline Haemaphysalis flava & China & HM193865 \\
\hline Haemaphysalis flava & Japan & AB075954 \\
\hline Haemaphysalis flava & China & JF758632 \\
\hline Haemaphysalis humerosa & Australian & AF132819 \\
\hline Haemaphysalis longicornis & China & JQ737087 \\
\hline
\end{tabular}


Supplementary Table S1. Continued

\begin{tabular}{|c|c|c|}
\hline Taxon & Locality & GeneBank accessions \\
\hline Haemaphysalis longicornis & China & JQ737090 \\
\hline Haemaphysalis longicornis & China & JQ737091 \\
\hline Haemaphysalis longicornis & China & JQ737092 \\
\hline Haemaphysalis Iongicornis & China & JQ737093 \\
\hline Haemaphysalis longicornis & China & JQ737096 \\
\hline Haemaphysalis longicornis & Australian & AF132820 \\
\hline Haemaphysalis longicornis & China & EU670048 \\
\hline Haemaphysalis longicornis & China & JF758631 \\
\hline Haemaphysalis longicornis & China & JF758635 \\
\hline Haemaphysalis punctata & Romania & FN394335 \\
\hline Haemaphysalis punctata & Romania & FN394336 \\
\hline Haemaphysalis punctata & Romania & FN394337 \\
\hline Haemaphysalis punctata & Romania & FN394338 \\
\hline Haemaphysalis punctata & Romania & FN394339 \\
\hline Haemaphysalis punctata & Romania & FN394340 \\
\hline Haemaphysalis punctata & Romania & FN394340 \\
\hline Haemaphysalis qinghaiensis & China & JQ737088 \\
\hline Haemaphysalis qinghaiensis & China & JQ737089 \\
\hline Haemaphysalis qinghaiensis & China & JQ737094 \\
\hline Haemaphysalis qinghaiensis & China & JQ737095 \\
\hline Haemaphysalis qinghaiensis & China & JQ737098 \\
\hline Haemaphysalis qinghaiensis & China & JQ737099 \\
\hline Haemaphysalis qinghaiensis & China & JQ737100 \\
\hline Hyalomma aegyptium & Belgium & AF132821 \\
\hline Hyalomma anatolicum anatolicum & China & JQ737067 \\
\hline Hyalomma asiaticum & China & JQ737072 \\
\hline Hyalomma asiaticum & China & JQ737073 \\
\hline Hyalomma asiaticum asiaticum & China & JQ737070 \\
\hline Hyalomma asiaticum asiaticum & China & JQ737071 \\
\hline Hyalomma detritum & China & JQ737068 \\
\hline Hyalomma detritum & China & JQ737069 \\
\hline Hyalomma detritum & Unknow & EU827695 \\
\hline Hyalomma detritum & Unknow & EU827696 \\
\hline Hyalomma detritum & Unknow & EU827694 \\
\hline Hyalomma dromedarii & China & JQ737066 \\
\hline Hyalomma dromedarii & Egypt & AF132822 \\
\hline Hyalomma dromedarii & Ethiopia & AJ437082 \\
\hline Hyalomma dromedarii & Ethiopia & AJ437080 \\
\hline Hyalomma dromedarii & Ethiopia & AJ437062 \\
\hline Hyalomma lusitanicum & Unknow & EU827739 \\
\hline Hyalomma lusitanicum & Unknow & EU827737 \\
\hline Hyalomma lusitanicum & Unknow & EU827735 \\
\hline Hyalomma lusitanicum & Unknow & EU827697 \\
\hline Hyalomma lusitanicum & Unknow & EU827699 \\
\hline Hyalomma lusitanicum & Unknow & EU827701 \\
\hline Hyalomma lusitanicum & Unknow & EU827703 \\
\hline Hyalomma lusitanicum & Unknow & EU827705 \\
\hline Hyalomma lusitanicum & Unknow & EU827742 \\
\hline Hyalomma marginatum & Unknow & EU827693 \\
\hline Hyalomma marginatum & Unknow & EU827692 \\
\hline Hyalomma marginatum & Ethiopia & AJ437100 \\
\hline Hyalomma marginatum & Ethiopia & AJ437098 \\
\hline
\end{tabular}


Supplementary Table S1. Continued

\begin{tabular}{|c|c|c|}
\hline Taxon & Locality & GeneBank accessions \\
\hline Hyalomma marginatum & Ethiopia & AJ437096 \\
\hline Hyalomma marginatum & Ethiopia & AJ437094 \\
\hline Hyalomma marginatum & Ethiopia & AJ437097 \\
\hline Hyalomma marginatum rufipes & Ethiopia & AF132823 \\
\hline Hyalomma rufipes & China & JQ737074 \\
\hline Hyalomma truncatum & Ethiopia & AF132824 \\
\hline Hyalomma truncatum & Ethiopia & AJ437090 \\
\hline Hyalomma truncatum & Ethiopia & AJ437088 \\
\hline Hyalomma truncatum & Ethiopia & AJ437086 \\
\hline Hyalomma truncatum & Ethiopia & AJ437084 \\
\hline Hyalomma truncatum & Ethiopia & AJ437089 \\
\hline Ixodes acutitarsus & Japan & AB105166 \\
\hline Ixodes acutitarsus & China & HM193862 \\
\hline Ixodes acutitarsus & China & HM193896 \\
\hline Ixodes asanumai & Japan & AB231674 \\
\hline Ixodes bakeri & South African & GU437873 \\
\hline Ixodes cornuatus & Australia & FJ571511 \\
\hline Ixodes fecialis & Australia & FJ571509 \\
\hline Ixodes granulatus & Unknow & AB231673 \\
\hline Ixodes granulatus & China & $J F 758633$ \\
\hline Ixodes hirsti & Australia & FJ571510 \\
\hline Ixodes holocyclus & Japan & AB075955 \\
\hline Ixodes lividus & United Kingdom & GU124743 \\
\hline Ixodes monospinosus & Japan & AB231672 \\
\hline Ixodes nipponensis & Japan & AB231671 \\
\hline Ixodes ovatus & Japan & AB231670 \\
\hline Ixodes pavlovskyi & Japan & AB231669 \\
\hline Ixodes persulcatus & China & HM193868 \\
\hline Ixodes persulcatus & China & HM193870 \\
\hline Ixodes persulcatus & China & HM193872 \\
\hline Ixodes persulcatus & China & HM193867 \\
\hline Ixodes persulcatus & China & HM193869 \\
\hline Ixodes persulcatus & China & HM193871 \\
\hline Ixodes persulcatus & China & JF758629 \\
\hline Ixodes persulcatus & Japan & AB073725 \\
\hline Ixodes philipi & Japan & AB231663 \\
\hline Ixodes philipi & Japan & AB231665 \\
\hline Ixodes philipi & Japan & AB231664 \\
\hline Ixodes philipi & Japan & AB231666 \\
\hline Ixodes pilosus & South African & GU437874 \\
\hline Ixodes ricinus & France & GU074940 \\
\hline Ixodes ricinus & France & GU074942 \\
\hline Ixodes ricinus & France & GU074944 \\
\hline Ixodes ricinus & France & GU074946 \\
\hline Ixodes ricinus & France & GU074948 \\
\hline Ixodes ricinus & France & GU074950 \\
\hline Ixodes ricinus & Romania & FN394342 \\
\hline Ixodes rubicundus & South African & GU437875 \\
\hline Ixodes scapularis & USA & GU074891 \\
\hline Ixodes turdus & Japan & AB231668 \\
\hline Ixodes uriae & Japan & AB087746 \\
\hline Ixodes vespertilionis & Japan & AB231667 \\
\hline
\end{tabular}


Supplementary Table S1. Continued

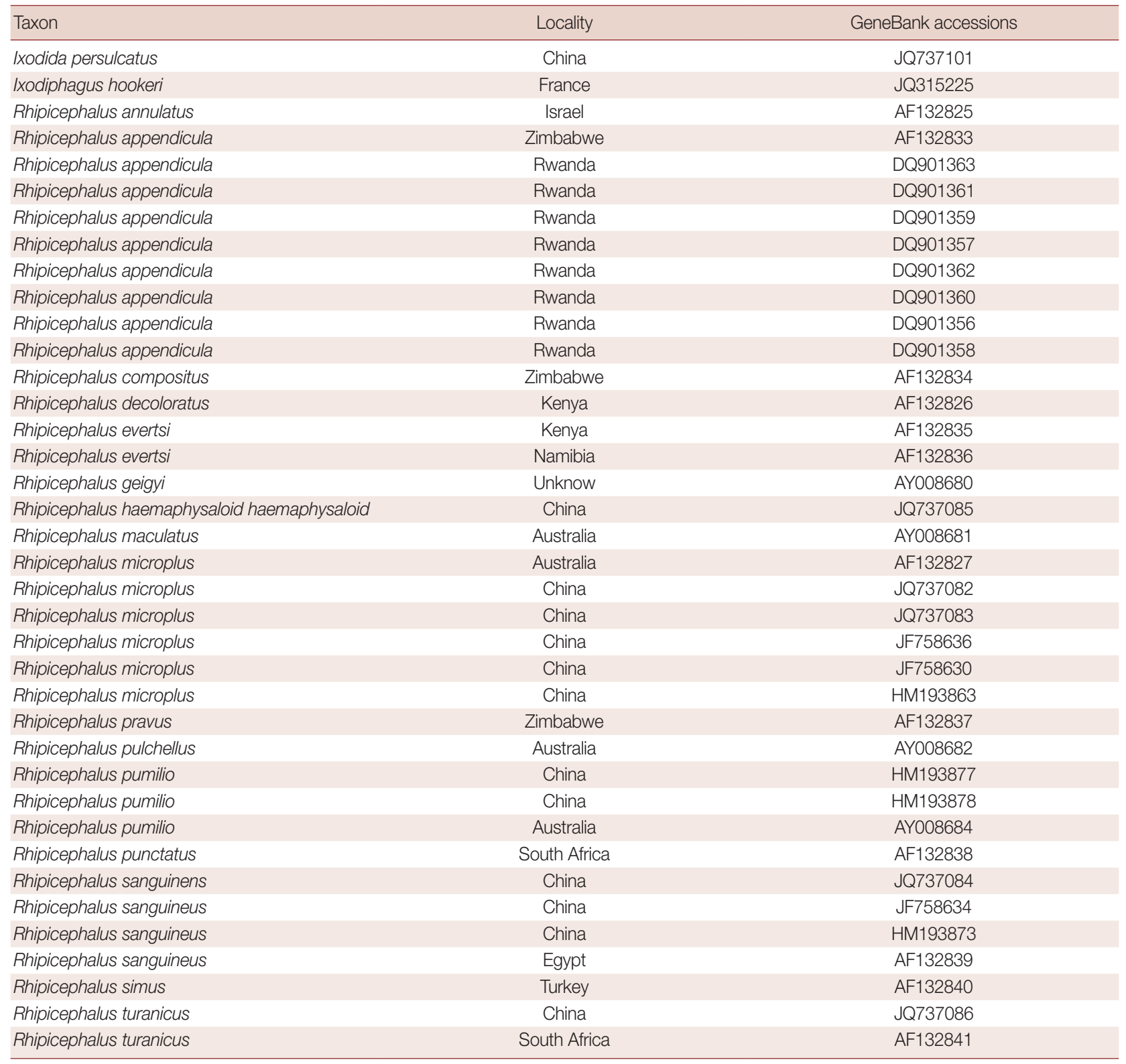

